\title{
DEVELOPMENT OF A THIRD GENERATION DS SUPERALLOY
}

\author{
T.Kobayashi, M.Sato, Y.Koizumi, H.Harada, T.Yamagata, \\ A.Tamura*, and J.Fujioka* \\ High Temperature Materials 21 Project, National Research Institute for Metals \\ 1-2-1 Sengen, Tsukuba Science City, Ibaraki 305-0047, Japan \\ ${ }^{*}$ Kawasaki Heavy Industries, Ltd. \\ 2-4-1 Hamamatsu-cho, Minato-ku, Tokyo 105-6116, Japan
}

\begin{abstract}
A third generation DS superalloy with creep strength as high as the second generation SC superalloys was developed. The alloy TMD-103 was designed by simply adding grain boundary strengthening elements, carbon and boron, to a third generation SC superalloy TMS-75 containing 5wt\% Re. The alloy was cast to columnar grained directionally solidified structure with solidification rate at $200 \mathrm{~mm} / \mathrm{h}$. Creep test was performed after solution and aging heat treatments. Typical creep-rupturc lives at $900^{\circ} \mathrm{C}-392 \mathrm{MPa}$ and $1040^{\circ} \mathrm{C}-137 \mathrm{MPa}$ being $519 \mathrm{~h}$ and $884 \mathrm{~h}$, respectively, which were equivalent with CMSX-4. Burner rig tests showed gond hot corrosinn and oxidation resistance. A DS hollow blade of a $2000 \mathrm{KW}$ class industrial gas turbine was successfully cast with TMD-103.
\end{abstract}

\section{Introduction}

The production cost of the advanced single crystal (SC) superalloys are becoming higher due to the complicated casting and heat treatment conditions and the resulting lower yields. It is practically very important to develop superalloys with higher cost-performance. The production cost of directionally solidified (DS) columnar grained superalloys is considerably lower than that of SC superalloys. However the creep strengths of the present DS superalloys are not competitive with the advanced SC superalloys. The so-called second generation DS superalloys with $3 w t \%$ Re, for example CM186LC [1], which is the strongest DS superalloy existing, are not stronger than the first generation SC superalloys.
In the present paper, a new class of DS superalloy with a high cost-performance, namely, the third generation DS superalloy is reported. The microstructures, creep and fatigue properties, and hot corrosion and oxidation properties are evaluated comparing with the present DS and SC superalloys.

\section{Alloy Design}

The third generation SC superalloy TMS-75, that was developed by some of the authors [2], was used as the base alloy. This alloy has excellent processability and phase stability as well as high creep strength and hot corrosion resistance. In this study, we simply added 0.07 wt \% carbon (C) and $0.015 \mathrm{wt} \%$ boron (B) to the TMS-75 as the grain boundary strengthening elements. The chemical compositions of the alloys are given in Table I with some typical DS and SC superalloys as references.

The carbon forms carbides in superalloys. It is estimated by our alloy design program (NRIM-ADP) that $\mathrm{MC}$ and $\mathrm{M}_{6} \mathrm{C}$ carbides are formed in TMD-103. It is also predicted that the $\mathrm{MC}$ carbide contains $\mathrm{Ta}$ as the main part of ' $\mathrm{M}$ '. In the $\mathrm{M}_{6} \mathrm{C}, \mathrm{W}$ and $M o$ are predicted to occupy ' $M$ '. The behavior of Re can not be predicted due to the lack of experimental data.

The carbide formations result in slight decreases of the solid solution strengthening elements in the $\gamma$ and $\gamma^{\prime}$ phases. Also the $\gamma^{\prime}$ fraction in the TMD-103 is predicted to become slightly smaller than TMS-75. However, the effects of these microstructural changes on the creep strength were estimated to be small. 
Table I Chemical compositions (wt \%) of TMD-103 and the base alloy TMS-75, with those of typical DS and SC superalloys.

\begin{tabular}{|c|c|c|c|c|c|c|c|c|c|c|c|c|c|}
\hline & $\mathrm{Ni}$ & $\mathrm{Co}$ & $\mathrm{Cr}$ & $\mathrm{Mo}$ & $\mathrm{W}$ & $\mathrm{Al}$ & $\mathrm{Ti}$ & $\mathrm{Ta}$ & $\mathrm{Hf}$ & $\mathrm{Re}$ & $\mathrm{C}$ & $\mathrm{B}$ & $\mathrm{Zr}$ \\
\hline $\begin{array}{c}\text { TMS-75 } \\
\text { (3rd SC) }\end{array}$ & Bal. & 12.0 & 3.0 & 2.0 & 6.0 & 6.0 & - & 6.0 & 0.1 & 5.0 & - & - & - \\
\hline $\begin{array}{c}\text { TMD-103 } \\
\text { (3rd DS) }\end{array}$ & Bal. & $\mathbf{1 2 . 0}$ & $\mathbf{3 . 0}$ & $\mathbf{2 . 0}$ & $\mathbf{6 . 0}$ & $\mathbf{6 . 0}$ & - & $\mathbf{6 . 0}$ & $\mathbf{0 . 1}$ & $\mathbf{5 . 0}$ & $\mathbf{0 . 0 7}$ & $\mathbf{0 . 0 1 5}$ & - \\
\hline $\begin{array}{c}\text { CMSX-4 } \\
\text { (2nd SC) }\end{array}$ & Bal. & 9.0 & 6.5 & 0.6 & 6.0 & 5.6 & 1.0 & 6.5 & 0.1 & 3.0 & - & - & - \\
\hline $\begin{array}{c}\text { CM186LC } \\
\text { (2nd DS) }\end{array}$ & Bal. & 9.0 & 6.0 & 0.5 & 8.0 & 5.7 & 0.7 & 3.0 & 1.4 & 3.0 & 0.07 & 0.015 & 0.005 \\
\hline $\begin{array}{c}\text { CM247LC } \\
\text { (1st DS) }\end{array}$ & Bal. & 9.2 & 8.1 & 0.5 & 9.5 & 5.6 & 0.7 & 3.2 & 1.4 & - & 0.07 & 0.015 & 0.015 \\
\hline $\begin{array}{c}\text { IN792Hf } \\
\text { (1st DS) }\end{array}$ & Bal. & 8.9 & 12.3 & 1.8 & 4.4 & 3.4 & 3.9 & 4.0 & 1.0 & - & 0.12 & 0.014 & 0.050 \\
\hline
\end{tabular}

\section{Casting and Heat Treatment Characteristics}

A TMS-75 master heat bar was melted and, after the C and B additions, cast to DS bars of $10 \mathrm{~mm}$ diameter with solidification rate at $200 \mathrm{~mm} / \mathrm{h}$. The microstructure was examined after single-step solution treatment at temperatures between 1225 and $1300^{\circ} \mathrm{C}$ for $2 \mathrm{~h}$ to find the optimum solution temperature. The DS bars were solution heat treated under thus selected standard condition; the solution treatment was performed at $1275^{\circ} \mathrm{C}$ for $5 \mathrm{~h}$ after heating at $1225^{\circ} \mathrm{C}$ for $1 \mathrm{~h}$ as a pre-homogenization to avoid any chance of incipient melting. A two-step aging treatment was performed, first at $1150^{\circ} \mathrm{C}$ for $4 \mathrm{~h}$ and second at $870^{\circ} \mathrm{C}$ for $20 \mathrm{~h}$, both followed by air-cooling.

Figure 1 shows the microstructures after solution heat treatment at $1275^{\circ} \mathrm{C}$ and $1300^{\circ} \mathrm{C}$. It is shown that almost all the $\gamma^{\prime}$ precipitates are dissolved at $1275^{\circ} \mathrm{C}$ and re-precipitated as fine $\gamma^{\prime}$, except for the eutectic $\gamma^{\prime}$ and the grain boundary $\gamma$ '. At $1300^{\circ} \mathrm{C}$, a perfect solution including the eutectic and grain boundary $\gamma^{\prime}$ is achieved. However, a small amount of incipient
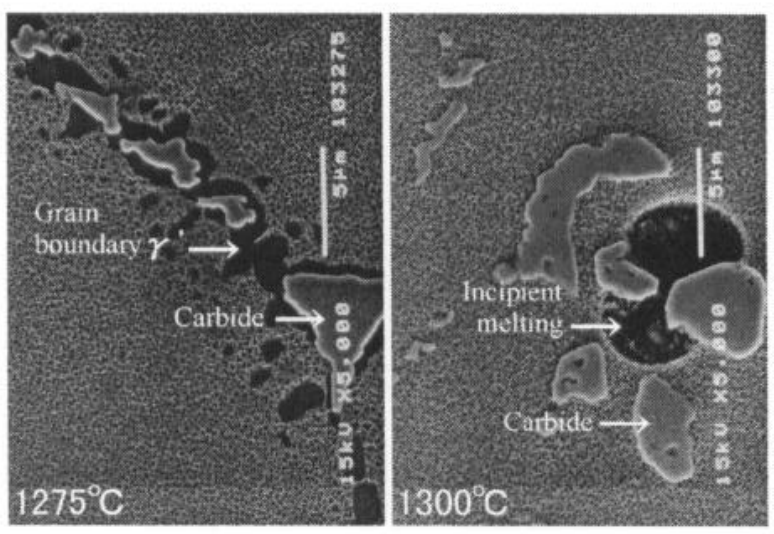

Figure 1: SEM micrographs of TMD-103 DS after solution heat treatment at $1275^{\circ} \mathrm{C}$ and $1300^{\circ} \mathrm{C}$.
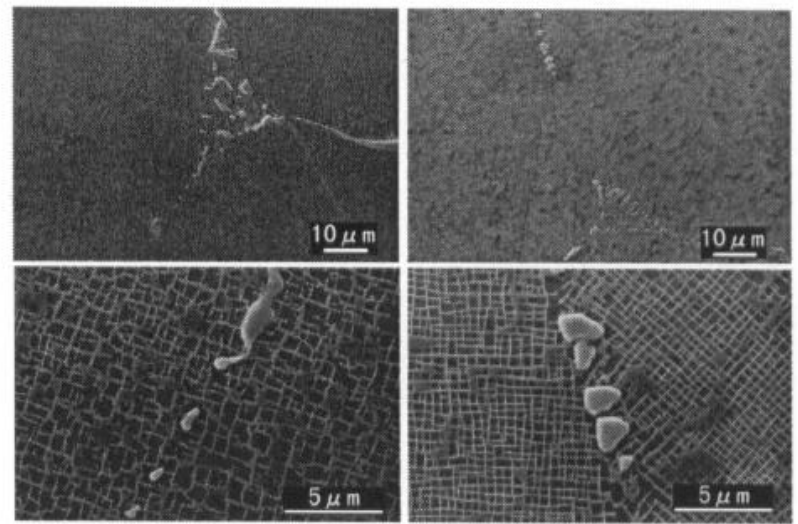

TMD-103 As Cast(DS)

TMD-103 As H T

Figure 2: SEM micrographs of as cast and as standard heat treated TMD-103 DS samples.

melting started to occur involving carbides, resulting in cavities formed during the following solidification. From these results, $1275^{\circ} \mathrm{C}$ was selected as the standard solution heat treatment temperature.

Figure 2 shows the microstructures in as cast and as standard heat treated (including aging) samples. The $\gamma^{\prime}$ precipitates became finer and their alignment became better after the standard heat treatment. The $\gamma^{\prime}$ size in as cast sample is rather small and of fairly regular shape. This must be due to the high $\operatorname{Re}$ content; $\operatorname{Re}$ reduces the $\gamma^{\prime}$ size because of its low diffusibity and high $\gamma / \gamma^{\prime}$ partitioning coefficient, e.g., 10:1 [4], both effectively prevent the $\gamma$ ' growth. Carbide(s) with bright contrast are observed mostly at grain boundaries and also in the interdendritic regions. The bright contrast suggests that the carbide(s) contain elements having higher atomic numbers, such as Ta, W, Mo and possibly Re.

The castability was evaluated with a DS hollow blade for a $2000 \mathrm{KW}$ class industrial gas turbine as shown in Figure 3. The 


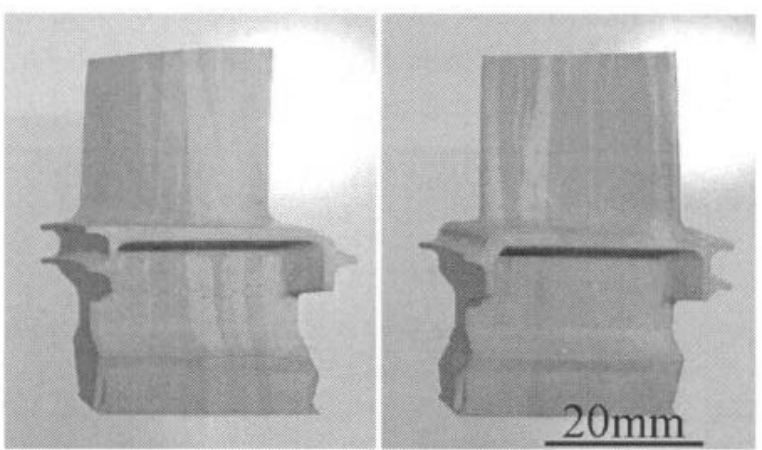

Figure 3: A DS hollow blade for an industrial gas turbine, cast with TMD-103.

solidification rate was again $200 \mathrm{~mm} / \mathrm{h}$. The normal inspection was carried out to examine the castings. It was found that sound castings were obtained without any defects. There are no difficulties so far in production of such DS blades.

\section{Mechanical Properties}

Creep tests were performed in short-term and long-term to estimate the strength level and phase stability with
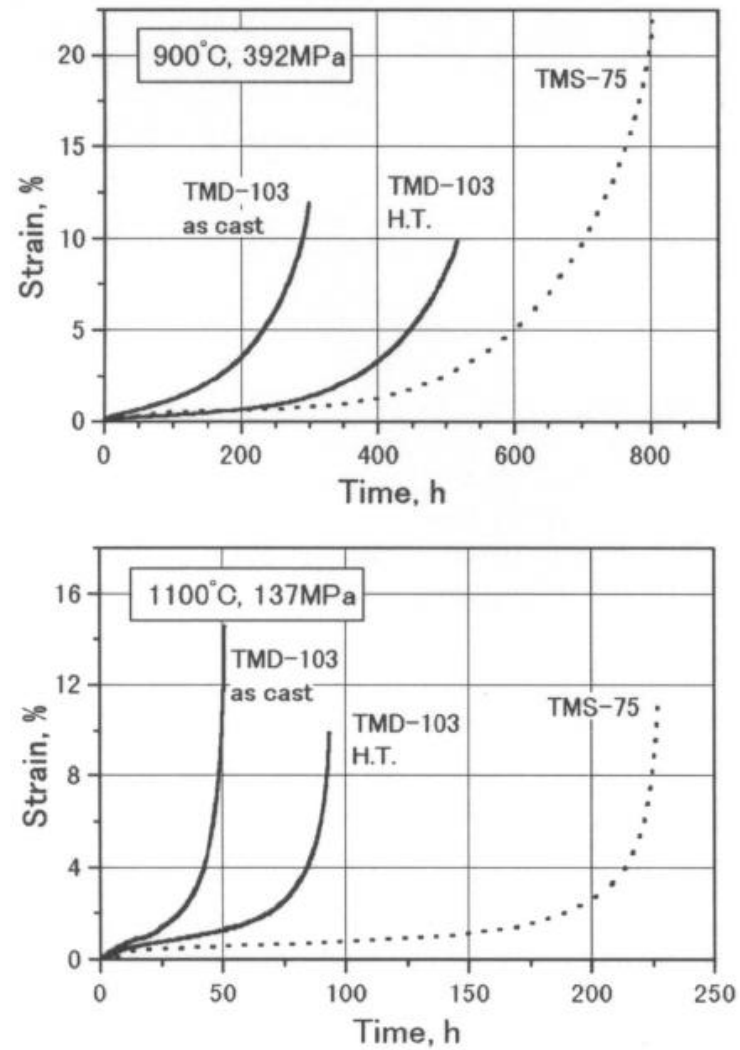

Figure 4: Creep curves of as cast and heat treated (HT) TMD-103 DS longitudinal samples, with those of TMS75 SC.

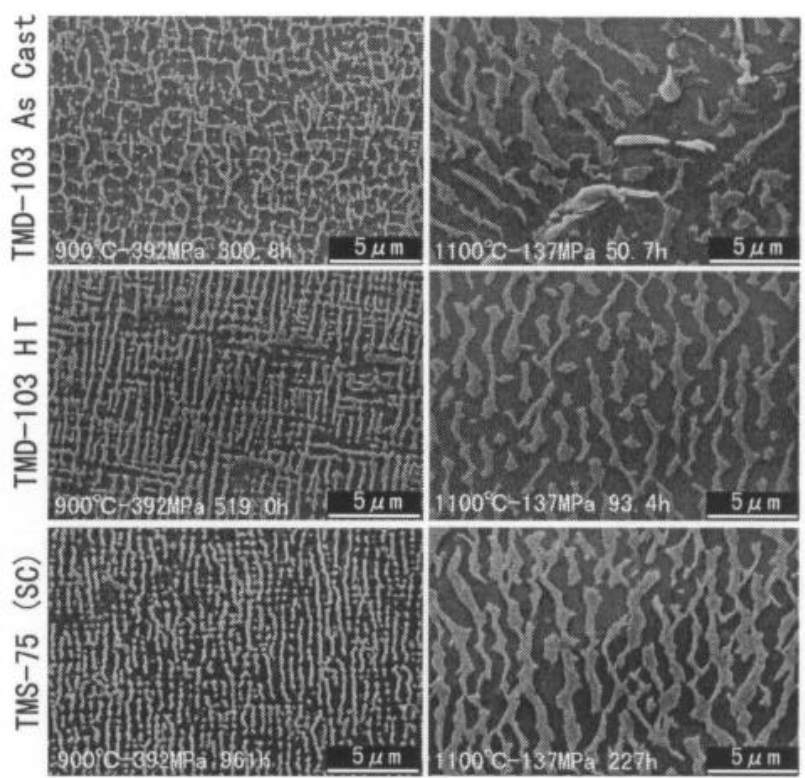

Figure 5: Microstructures in creep ruptured samples.

temperatures ranging $900-1100^{\circ} \mathrm{C}$. A newly developed optical monitoring system was used for measuring the high temperature creep strain. Low cycle fatigue tests were also conducted at $950^{\circ} \mathrm{C}$ in air with $\mathrm{R}$ ratio of -1 and strain rate of $0.1 \% / \mathrm{sec}$.

\section{Creep Test (Short-Term)}

In Figure 4 the creep curves of as cast and heat treated TMD103 DS longitudinal samples are compared with those of TMS-75 SC. The creep-rupture lives of heat treated DS samples are about $40 \%$ to $60 \%$ of those in TMS- 75 .

Figure 5 represents the microstructures in the creep-ruptured samples. The creep conditions and rupture lives are given in the figure. The microstructures in TMD-103 as cast samples

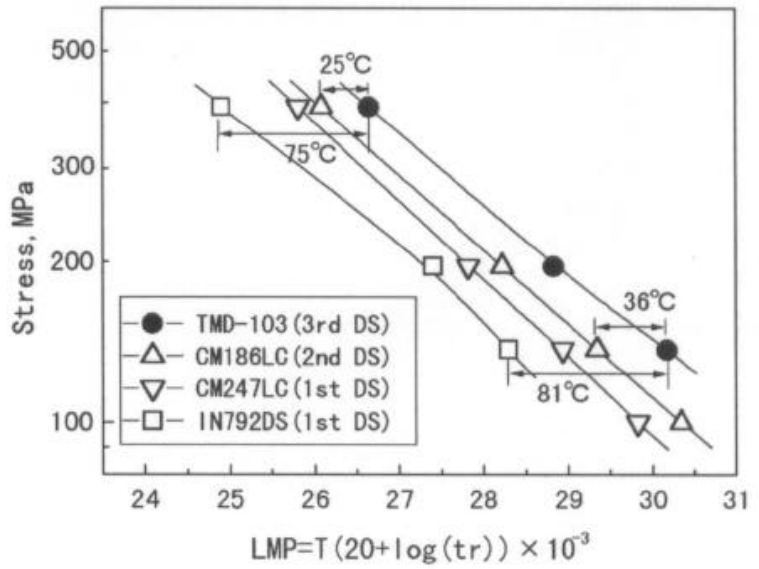

Figure 6: Comparison of creep-rupture strengths among first, second, and third generation DS superalloys. 


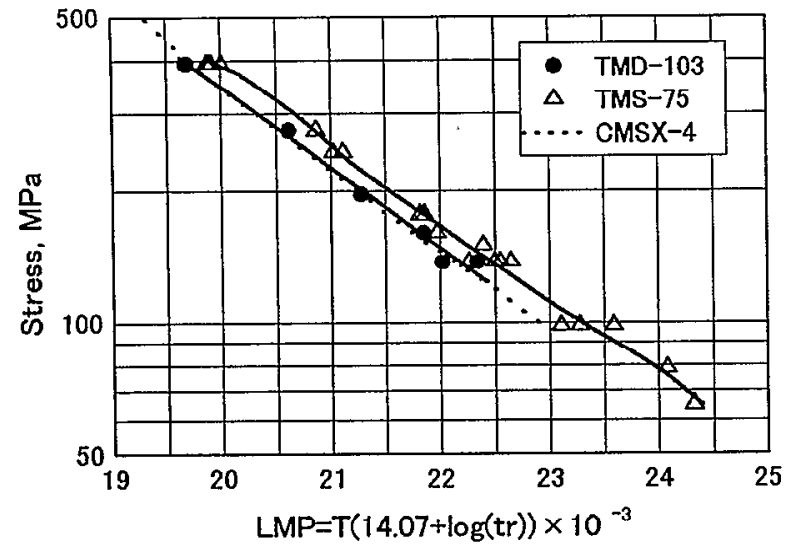

Figure 7: Comparison of creep-rupture strengths including long-term data with re-fitted Larson Miller Parameter $(\mathrm{C}=14.07)$.

are coarser than the others in the both creep conditions, which must cause the shorter creep-rupture lives. The heat treated DS sample has very similar microstructures to those in TMS-75 SC but has shorter creep-rupture lives. This should be attributed to the remaining undissolved eutectic $\gamma^{3}$ phase and the presence of grain boundaries in the TMD-103 DS samples. In Figure 6 a comparison of creep-rupture strengths is made among first, sccond, and third generation DS superalloys. It is demonstrated that the third generation DS superalloy TMD103 has 25 to $36^{\circ} \mathrm{C}$ higher temperature capability than the second generation DS superalloy CM186LC. When comparison is made with IN792Hf DS the capability of our alloy is higher by 75 to $81^{\circ} \mathrm{C}$.

\section{Creep Test (Long-Term)}

In Figure 7 the creep-rupturc results of TMD-103 and TMS-75 including some long-term data over $1000 \mathrm{~h}$ are compared with the CMSX-4 data with re-fitted Larson Miller Parameter at

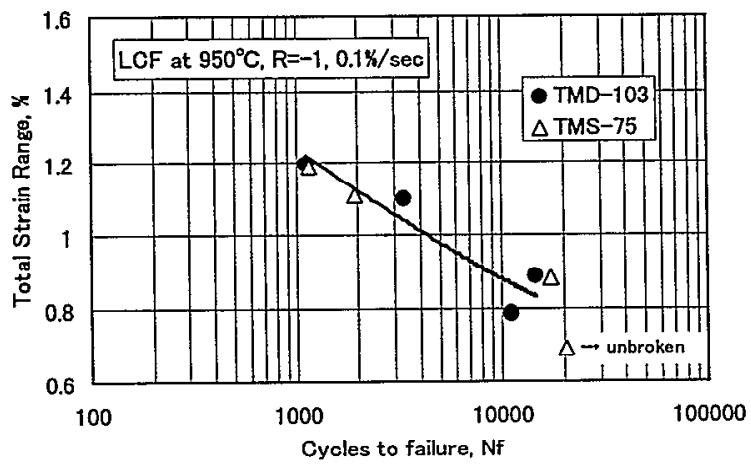

Figure 8: Low cycle fatigue failure data of TMD-103 DS and TMS-75 SC at $950^{\circ} \mathrm{C}$.
$\mathrm{C}=14.07$ [5]. The longest data of TMD-103 and TMS-75 are about $6300 \mathrm{~h}$ and $7800 \mathrm{~h}$, respectively. The creep-rupture strength of TMD-103 was found to be as strong as the second generation SC superalloy CMSX-4 for thousands hours.

\section{Low Cycle Fatigue Test}

Figure 8 shows the low cycle fatigue failure results of TMD103 and TMS-75. Although data points were not enough and scattering, the low cycle fatigue property of TMD-103 was almost as good as SC superalloy TMD-75.

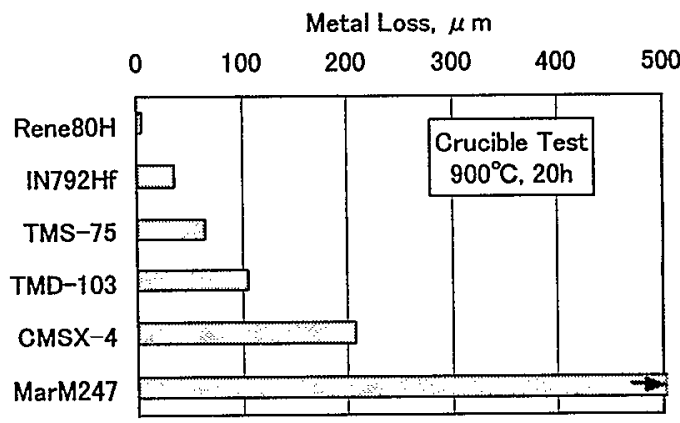

Figure 9: Crucible test results at $900^{\circ} \mathrm{C}, 20 \mathrm{~h}$ with $75 \% \mathrm{Na}_{2} \mathrm{SO}_{4}+25 \% \mathrm{NaCl}$ mixed salt.

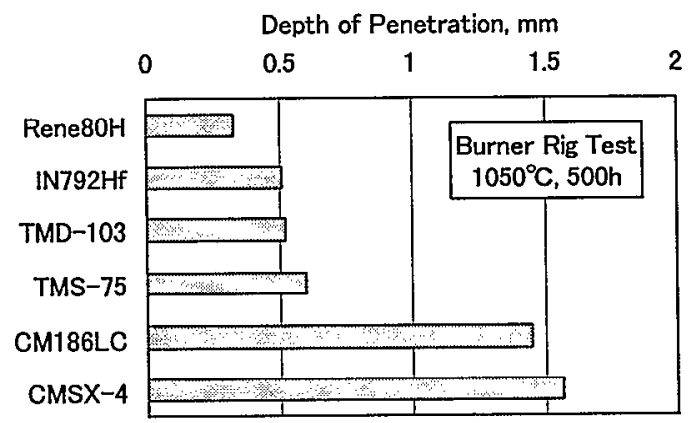

Figure 10: Bumcr rig hot corrosion test results at $1050^{\circ} \mathrm{C}$, $500 \mathrm{~h}$ with kerosene fuel and corrosive ingredients $(\mathrm{S}, \mathrm{Cl}$, $\mathrm{Na}$, etc.).

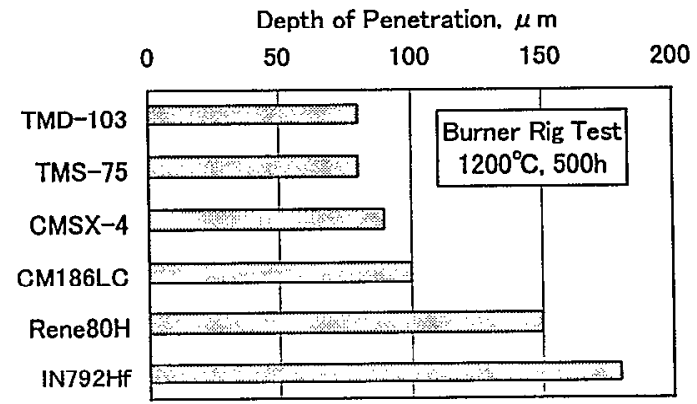

Figure 11: Burner rig oxidation test results at $1200^{\circ} \mathrm{C}$, $500 \mathrm{~h}$ with kerosene fuel only. 


\section{Environmental Properties}

In high temperature corrosion tests, varied results are often given at the different condition. One crucible test and two burner rig tests were conducted to evaluate the environmental properties of TMD-103 relatively.

Crucible test were performed at $900^{\circ} \mathrm{C}$ for $20 \mathrm{~h}$ with $75 \% \mathrm{Na}_{2} \mathrm{SO}_{4}+25 \% \mathrm{NaCl}$ mixed salt in air atmosphere.

Burner rig tests were performed with a hot corrosive condition and an oxidative condition. In the hot corrosion test, to simulate a severe hot corrosive environment in a heavy duty industrial gas turbine, some sulfuric oil and artificial seawater were added into kerosene burner at gas temperature of $1050^{\circ} \mathrm{C}$ and exposure of $500 \mathrm{~h}$. The oxidation test was run at $1200^{\circ} \mathrm{C}$ for $500 \mathrm{~h}$ without the addition of corrosive ingredients.

Alloys IN792Hf, CMSX-4, etc., were also tested under the same condition as references.

\section{Crucible Test}

In Figure 9 the crucible test results are compared with some reference alloys. TMD-103 showed a good corrosion resistance, forming a protective scale like a $\mathrm{Cr}_{2} \mathrm{O}_{3}$-former type in spite of the low $\mathrm{Cr}$ content.

\section{Burner Rig Test (Hot Corrosion)}

In Figure 10 the burner rig hot corrosion test results are represented with several DS and SC superalloys. There is a general tendency that the alloy with higher $\mathrm{Cr}$ content has higher hot corrosion resistance. However, TMD-103 which has only $3 \mathrm{wt} \% \mathrm{Cr}$ showed the hot corrosion resistance comparable with IN792Hf containing $12.5 \mathrm{wt} \% \mathrm{Cr}$. This is due to the $5 \mathrm{wt} \%$ $\operatorname{Re}$ content. As already reported [6], $\mathrm{Re}$ is effective in improving hot corrosion resistance as well as creep strength.

\section{Burner Rig Test (Oxidation)}

Figure 11 shows the burner rig oxidation test results. At higher temperature, alloys with lower $\mathrm{Cr}$ and higher $\mathrm{Al}$ content tend to provide the good resistibility. On the other hand, most of corrosion-resistible alloys with higher $\mathrm{Cr}$ content, as Rene80H and IN792Hf, show poor resistibility at such conditions. These behaviors are generally explained with the balance of oxidation and sulfidation, and with the scale type of $\mathrm{Al}_{2} \mathrm{O}_{3}$ former or $\mathrm{Cr}_{2} \mathrm{O}_{3}$-former.

In this condition TMD-103 showed also a good performance. These results represent that TMD-103 has a good resistibility in both the hot corrosive and oxidative environment.
Conclusions

A third generation DS superalloy TMD-103 was designed as a high cost-performance superalloy and evaluated experimentally. The following results have been obtained;

(1) TMD-103 has about $36^{\circ} \mathrm{C}$ higher temperature capability than the second generation DS superalloy CM186LC at stress level of $137 \mathrm{MPa}$.

(2) Long-term creep-rupture strength of the alloy is equivalent with second generation SC superalloy CMSX-4.

(3) Low cycle fatigue property of the alloy is almost the same as that of TMS-75 SC at $950^{\circ} \mathrm{C}$ in air.

(4) Hot corrosion resistance of the alloy is found to be equivalent with IN792Hf $(12.5 \mathrm{wt} \% \mathrm{Cr})$ in spite of the low (3wt\%) Cr content.

(5) Oxidation resistance of the alloy is as good as or better than CMSX-4.

(6) Heat treatment of the alloy is simple, and a DS hollow blade for an industrial gas turbine was successfully cast with the alloy.

TMD-103 was thus thought to be promising as a high costperformance turbine blade material for industrial gas turbines, marine gas turbines, and aero-engines.

Further work on modification of TMD-103 is being conducted.

\section{Acknowledgments}

This work is a part of the KHI-NRIM collaborative research in the High Temperature Materials 21 Project.

The authors wish to thank Dr.N.Akikawa, Mr.T.Takenaka, and Mr.H.Ishihara of KHI (Akashi Works) for their conducting the burner rig tests.

The authors also acknowledge the ROSS \& CATHERALL LTD. for supplying the melting stock.

\section{References}

1. K.Harris, et al., "Development of the Rhenium Containing Superalloys CMSX-4 \& CM186LC for Single Crystal Blade and Directionally Solidified Vane Applications in Advanced Turbine Engines", Superalloys 1992 (Warrendale, PA: TMS, 1992), 297-306.

2. T.Kobayashi, et al., "Design of High Rhenium Containing Single Crystal Superalloys with Balanced Intermediate and High Temperature Creep Strengths", Advances in Turbine Materials, Design and Manufacturing (Newcastle upon Tyne, U.K., 4-6 November 1997), 766-773. 
3. H.Harada, et al., "Alloy Design for Nickel-base Superalloys", High Temperature Alloys for Gas Turbines 1982 (Liege, Belgium, 4-6 October 1982), 721-735.

4. H.Harada, et al., "Phase Calculation and Its Use in Alloy Design Program for Nickel-base Superalloys", Superalloys 1988 (Warrendale, PA: TMS, 1988), 733-742.

5. C.K.Bullough, et al., "The Characterization of The Single Crystal Superalloy CMSX-4 for Industrial Gas Turbine Blading Applications", Materials for Advanced Power Engineering 1998 (Liege, Belgium, 5-7 October 1998), 861878 .

6. G.L.Erickson, "The Development and Application of CMSX-10", Superalloys 1996 (Warrendale, PA: TMS, 1996), $35-44$. 